\title{
Value of ST Segment Changes in 12 Lead ECG to Detect Proximal Versus Distal Right Coronary Artery Occlusion in Acute Inferoposterior Myocardial Infarction
}

\author{
MOSTASHIRUL HAQUE, SAJAL KRISHNABANERJEE, CHOWDHURY MESHKAT AHMED, S.M.AHSAN HABIB, \\ AHMED SHAFIQUL HOSSAIN, MD. GOLAM RAHMAN, MD. NASIMUL BARI, AYESHARAFIQ, \\ MD. SIRAJUL ISLAM, GOBINDA CHANDRA ROY \\ Department of Cardiology, Bangabandhu Sheikh Mujib Medical University (BSMMU), Dhaka
}

Address for Correspondence: Dr. Mostashirul Haque, Derpartment of Cardiology, Bangabandhu Sheikh Mujib Medical University, Dhaka, e-mail-mustashirul_haque@yahoo.com

\begin{abstract}
:
Background: A history of ischemic-type discomfort \& the initial 12- lead ECG are the primary tools for screening patients with acute myocardial infarction in the emergency department. ST elevation in inferior leads indicates an evolving myocardial infarction of the inferoposterior wall. The outcome of patients with inferoposterior myocardial infarction due to occlusion of right coronary artery depends mainly on the location of occlusion (distal versus proximal).

Hypothesis: Value of ST-segment depression in lateral leads (I and aVL) and ST-segment changes in lead $V_{1}$ to predict the site of right coronary artery occlusion in the case of an inferoposterior myocardial infarction.

Objective: To predict the site of right coronary artery (RCA) occlusion (proximal or distal) in acute inferoposterior myocardial infarction by ST segment depression in leads 1 \& aVL and ST-segment changes(is electric/elevated or depressed) in $V_{1}$.

Methods and Results: A total of fifty four patients of ST-segment elevation inferoposterior wall AMI due to suspected RCA occlusion, admitted within 12 hours of onset of chest pain, and subsequently underwent coronary angiography during hospitalization, were selected for the study. Patients were divided into two groups on the basis of angiographic findings: proximal RCA occlusion (group I) and distal RCA occlusion (group II). A 12 lead ECG was taken on admission. ST segment deviation in lateral leads (I \& aVL) as well as in precordial lead $\left(V_{1}\right)$ was calculated. Isoelectric or elevated ST-segment in $V_{1}$ predicted proximal RCA occlusion whereas depressed ST-segment predicted distal RCA occlusion. It was demonstrated that, STsegment changes in precordial lead $\left(V_{1}\right)$ was a sensitive \& specific marker to discriminate proximal \& distal RCA occlusion in inferoposterior wall AMI with high positive \& negative predictive value, but ST-segment changes in lateral leads (I \& aVL) although more specific for proximal RCA occlusion did not seem to be of clinical value due to its low sensitivity.
\end{abstract}

Key words: Inferoposterior wall AMI, RCA occlusion, ST-segment changes.

Introduction:

ST elevation in inferior leads indicates an evolving myocardial infarction of the inferoposterior wall. This infarction in nearly $80 \%$ of cases is due to right coronary artery occlusion and the rest by the occlusion of the left circumflex artery. ${ }^{5}$ The outcome of patients with right coronary as a culprit artery is determined mainly by the location of occlusion. Proximal RCA occlusion usually leads to right ventricle involvement and this determines worse prognosis and higher mortality. 5,17 Additionally it is more often accompanied by conduction AV disturbances. ${ }^{1}$ Therefore it is extremely important from the clinical point of view to recognize where the location of occlusion to determine the optimal treatment and management of evaluated patient.
ECG criteria based on 12 lead ECG have been studied to determine the location of RCA occlusion. ${ }^{15}$

In inferoposterior myocardial infarction due to occlusion of RCA, ST changes in inferior leads (ST elevation in II, III and $\mathrm{aVF}$ ) are the key to recognizing the injured area because the injury vector of the affected area is directed predominantly down ward. However as the injury vector is also directed slightly to the right it provokes ST depression in I and aVL lead. In the case of right ventricular involvement the injury vector points more to the right and more anteriorly. ${ }^{8}$

To identify the culprit artery in the case of myocardial infarction of inferoposterior zone there is ST depression in lateral leads, I \& aVL. 2,3,6,11,12 Ability to recognize RCA 
versus LCX occlusion with 95\% accuracy based on ST changes in 12- lead ECG. ${ }^{9}$

However the presumptive diagnosis of a culprit artery gives only partial information required to predict the need of urgent revascularization procedures. From the clinical point of view the location of RCA occlusion is the next most important information in the case of the inferior MI due to occlusion of this artery.

Therefore, once determined by ECG with high probability that RCA is the culprit artery, then other ECG criteria may be used to predict proximal versus distal occlusion.

The right ventricular involvement that usually accompanies the proximal RCA occlusion may be determined on the basis of ST changes in right precordial leads. ${ }^{16}$ The changes in these leads are very specific but they disappear in the early stage of the evolution of myocardial infarction. Furthermore, in some cases there are no changes in right precordial leads due to the presence of concomitant lateral or posterior involvement. ${ }^{13}$ Another important disadvantage of the diagnosis based on right precordial leads is that these leads are often not recorded in the majority of emergency room. Thus the predictive accuracy of these changes is of limited value. In a published study Turhan et al. evaluated the value of aVL in the diagnosis of right ventricular involvement with acute myocardial infarction. ${ }^{15}$ They found that ST depression of over $1 \mathrm{~mm}$ in aVL was very sensitive \& specific for right venticular involvement in patients with acute myocardial infarction (compared to the diagnosis of right ventricular infarction based on changes in the right precordial leads ST elevation $>1 \mathrm{~mm}^{\text {in }} \mathrm{V}_{4} \mathrm{R}$ ).

Fiol et al. studied to compare this criterion (ST-segment depression in aVL more or less than $5.5 \mathrm{~mm}$ ) to a new criterion assessing simultaneous changes both in I and aVL leads (ST depression more or less than $5.5 \mathrm{~mm}$ ). This new criterion allowed to increase the specificity \& positive predictive value to predict the proximal RCA occlusion and more sensitive with high negative predictive value to predict distal RCA occlusion. The criterion of ST segment changes in $\mathrm{V}_{1}$ (ST segment isoelectric/elevated or depressed) has the highest accuracy for distinguishing proximal versus distal RCA occlusion. Isoelectric or elevated ST segment in $\mathrm{V}_{1}$ highly predictable for proximal RCA occlusion \& ST-segment depression in $\mathrm{V}_{1}$ for distal RCA occlusion in patients with acute inferoposterior MI. The combination of two new criteria analyzed together (sum of ST segment depression in $\mathrm{I}$ and $\mathrm{aVL}>5.5 \mathrm{~mm}$ and ST iso-electric or elevated in $\mathrm{V}_{1}$ ) has increased specificity and positive predictive value to $100 \%$ to detect proximal
RCA occlusion but significantly decreased utility of this combination in clinical practice due to low sensitivity.

.Right ventricular infarction (RVI) is associated with considerable morbidity \& mortality, and its presence defines high risk subgroups of patients with inferior wall acute myocardial infarction. Without early aggressive reperfusion therapy in these patients, a significantly increased risk of major complications and in hospital death has been reported. ${ }^{17}$

Proximal RCA occlusion is accepted as the culprit most commonly responsible for RVI. ${ }^{4}$ There is increased incidence of bradyarrhythmia in patients with RVI. Similarly high grade AV block may lead to loss of AV synchrony with right ventricle under filling \& further decline in right ventricle \& left ventricle stroke volume. This determines worse prognosis \& higher mortality.

Available information from this study has provided rationale to conduct the study. The study result will accrue the benefit to the society by providing information to emergency physicians regarding location of RCA occlusion in acute inferoposterior myocardial infarction by simple, non-invasive ECG criteria.

\section{Methods:}

A total of fifty four patients of ST-segment elevation inferoposterior wall AMI due to suspected RCA occlusion who were admitted to Coronary Care Unit within 12 hours of onset of chest pain, and subsequently underwent coronary angiography during hospitalization, were studied. Patients were divided into two groups according to the angiographic findings: group I $(n=30)$ included proximal RCA occlusion, Group II $(n=24)$ included distal RCA occlusion. Patient were excluded if previous myocardial infarction, left bundle branch block or right bundle branch block, left ventricular hypertrophy or right ventricular hypertrophy, patients with contraindication to CAG, patient having lesion in $>1$ sites (proximal or distal RCA), patient having lesions other than proximal or distal RCA, patient having nondominant or codominant RCA, acute myocarditis / pericarditis.

Study procedure: Informed written consent was taken from each subject. Initial evaluation of the patients were done by history, clinical examination and relevant investigations e.g. cardiac markers- troponins and CK-MB. Demographic data (age, sex, height, weight) were recorded. Risk factor profile including hypertension, diabetes, dyslipidemia, family history of coronary artery disease and smoking were noted. 
Clinical profile and in hospital complications like hypertension, acute left heart failure, conduction disturbances, cardiac arrest etc were noted.

A standard 12 leads ECG were recorded at a paper speed of $25 \mathrm{~mm} / \mathrm{s}$ and a voltage of $10 \mathrm{~mm} / \mathrm{mv}$ at the time of admission. ST changes were measured at 20, 40, 60 and 80 $\mathrm{ms}$ from the $\mathrm{J}$ point in all the leads. Measurements were made to the nearest $0.5 \mathrm{~mm}(0.05 \mathrm{mv})$; magnifying glass was used. The TP segment in the ECG was used as an iso electric line, and ST elevation or depression of $>0.5 \mathrm{~mm}$ $(0.05 \mathrm{mv})$ was considered abnormal. Therefore, ST segment between $<0.5 \mathrm{~mm}$ depression or $>0.5 \mathrm{~mm}$ elevation was considered as iso electric. Here the value of ST changes in conventional 12 lead ECG to predict the location of occlusion in right coronary artery was studied. The following ECG criteria were assessed:

a. ST changes in aVL lead (dichotomize at $1 \mathrm{~mm}$ ).

b. The sum of ST changes in I \& aVL lead (dichotomize at the value of $5.5 \mathrm{~mm}$ ). c. ST changes in $V_{1}$ lead (isoelectric / elevated or depressed).

All the criteria mentioned above were selected before ECG recording were evaluated.The specificity, sensitivity, positive and negative predictive values of these ECG criteria were evaluated to determine their association with the location of occlusion in RCA.

Coronary angiography (CAG): All the studied patients underwent CAG. Angiographic finding were evaluated. Only patients with total occlusion or clear critical stenosis in one vessel (right coronary artery) were recruited. Critical stenosis is defined as over 70\% narrowing of coronary artery lumen diameter by visual inspection. Patients were divided into two groups according to the location of occlusion; proximal (before right ventricle artery) and distal (after acute marginal artery). None of the subjects had occlusion between these two branches.

Results are shown in the following tables.

Table-I

Baseline characteristics of the study patients $(n=54)$.

\begin{tabular}{rcccccc}
\hline Age in years & \multicolumn{2}{c}{ Group I $(\mathrm{n}=30)$} & \multicolumn{2}{c}{ Group II(n=24) } & P value \\
& $\mathrm{N}$ & $\%$ & $\mathrm{~N}$ & $\%$ & \\
\hline $30-40$ & 1 & 3.3 & 2 & 8.3 & \\
$41-50$ & 5 & 16.7 & 4 & 16.7 & \\
$51-60$ & 13 & 43.3 & 11 & 45.8 & \\
$61-70$ & 8 & 26.7 & 6 & 25.0 & $0.640^{\mathrm{NS}}$ \\
$>70$ & 3 & 10.0 & 1 & 4.2 & \\
Mean \pm SD & \multicolumn{2}{c}{$57.9 \pm 10.2$} & \multicolumn{2}{c}{$56.5 \pm 10.3$} & $(37-85)$ \\
Range (min - max) & \multicolumn{7}{c}{$(40-85)$} & \multicolumn{7}{c}{ ma }
\end{tabular}

P value reached from unpaired Student's test

\begin{tabular}{lccccc}
\hline Sex & $\mathrm{N}$ & $\%$ & $\mathrm{n}$ & $\%$ & \\
\hline Male & 23 & 76.7 & 17 & 70.8 & $0.626^{\mathrm{NS}}$ \\
Female & 7 & 23.3 & 7 & 29.2 & \\
\hline
\end{tabular}

$\mathrm{P}$ value reached from chi square test

\begin{tabular}{lccccc}
\hline Risk factors & $\mathrm{n}$ & $\%$ & $\mathrm{n}$ & $\%$ & \\
\hline Smoker & 19 & 63.3 & 16 & 66.7 & $0.798^{\mathrm{NS}}$ \\
Hypertension & 17 & 56.7 & 14 & 58.3 & $0.625^{\mathrm{NS}}$ \\
Diabetes & 15 & 50.0 & 13 & 54.2 & $0.001^{\mathrm{S}}$ \\
Dyslipidaemia & 12 & 40.0 & 10 & 41.7 & $0.180^{\mathrm{NS}}$ \\
Family history & 11 & 36.7 & 9 & 37.5 & $0.495^{\mathrm{NS}}$ \\
\hline
\end{tabular}

(table continued) 
P value reached from Chi square test

\begin{tabular}{lccccc}
\hline Symptoms & $\mathrm{n}$ & $\%$ & $\mathrm{n}$ & $\%$ & \\
\hline Chest pain & 25 & 83.3 & 18 & 75.0 & $0.449^{\mathrm{NS}}$ \\
Shortness of breath & 16 & 53.3 & 10 & 41.7 & $0.393^{\mathrm{NS}}$ \\
Sweating & 15 & 50.0 & 10 & 41.7 & $0.708^{\mathrm{NS}}$ \\
Vomiting & 14 & 46.7 & 9 & 37.5 & $0.528^{\mathrm{NS}}$ \\
Nausea & 11 & 36.7 & 5 & 20.8 & $0.444^{\mathrm{NS}}$ \\
Dizziness & 9 & 30.0 & 4 & 16.7 & $0.333^{\mathrm{NS}}$ \\
Epigastric discomfort & 8 & 26.7 & 7 & 29.2 & $0.231^{\mathrm{NS}}$ \\
\hline
\end{tabular}

P value reached from Chi square test

\begin{tabular}{lccccc}
\hline & Mean & \pm SD & Mean & \pm SD & \\
\hline Duration of pain (hour) & 7.1 & \pm 2.2 & 6.5 & \pm 2.4 & $0.409^{\mathrm{NS}}$ \\
Range (min - max) & $(3$ & $-11)$ & $(3$ & $-11)$ & \\
P value reached from unpaired Student’s t test & & & & \\
In hospital complication & $\mathrm{N}$ & $\%$ & $\mathrm{n}$ & $\%$ & \\
No complication & 8 & 26.7 & 14 & 58.3 & $0.018^{\mathrm{s}}$ \\
Had complications & 22 & 73.3 & 10 & 41.7 & \\
Hypotension & 7 & 23.3 & 4 & 16.7 & $0.545^{\mathrm{NS}}$ \\
Acute LVF & 3 & 10.0 & 3 & 12.5 & $0.771^{\mathrm{NS}}$ \\
Cardiogenic Shock & 2 & 6.7 & 2 & 8.3 & $0.816^{\mathrm{NS}}$ \\
Cardiac arrest & 2 & 6.7 & 1 & 4.2 & $0.690^{\mathrm{NS}}$ \\
Sinus bardycardia & 2 & 6.7 & 0 & 0.0 & $0.197^{\mathrm{NS}}$ \\
$1^{\circ} \mathrm{HB}$ & 2 & 6.7 & 0 & 0.0 & $0.197^{\mathrm{NS}}$ \\
$3^{\circ} \mathrm{HB}$ & 4 & 13.3 & 0 & 0.0 & $0.063^{\mathrm{NS}}$ \\
\hline
\end{tabular}

$P$ value reached from chi square test

\begin{tabular}{lccccc}
\hline LVEF & $\mathrm{n}$ & $\%$ & $\mathrm{~N}$ & $\%$ & \\
\hline$\leq 50$ & 2 & 6.7 & 4 & 16.7 & \\
$50-60$ & 19 & 63.3 & 13 & 54.2 & $0.498^{\text {ns }}$ \\
$\geq 60$ & 9 & 30.0 & 7 & 29.2 & \\
\hline
\end{tabular}

$\mathrm{P}$ value reached from Chi square test

\section{Table II}

Sensitivity, specificity, positive and negative predictive values of the "IST in aVL ( $1 \mathrm{~mm})$, sum of ${ }^{-} \mathrm{ST}$ in I+aVL( 35.5 $\mathrm{mm}), V_{1}$ iso-electric or elevated and sum of $S T$ in $I+a V L 35.5 \mathrm{~mm}$ with $V_{1}$ iso-electric or elevated predicting lesion in proximal $R C A$.

\begin{tabular}{lcccc}
\hline Validity test & $\mathrm{aVL}$ & $\mathrm{I}+\mathrm{aVL}$ & $\mathrm{V}_{1}$ & $(\mathrm{I}+\mathrm{aVL})$ with $\mathrm{V}_{1}$ \\
\hline Sensitivity & 33.3 & 30.0 & 66.7 & 13.3 \\
Specificity & 75.0 & 87.5 & 87.5 & 100.0 \\
PPV & 62.5 & 75.0 & 87.5 & 100. \\
NPV & 47.4 & 50.0 & 66.7 & 48.0 \\
\hline
\end{tabular}




\section{Table III}

Sensitivity, specificity, positive and negative predictive values of the ${ }^{-} \mathrm{ST}$ in $\mathrm{aVL}(<1 \mathrm{~mm})$, sum of ${ }^{-} \mathrm{ST}$ in $I+a V L(<5.5 \mathrm{~mm}), V_{1}$ descendent and sum of ${ }^{-} S T$ in $I+a V L<5.5 \mathrm{~mm}$ with $V_{1}$ descendent for predicting lesion in distal RCA.

\begin{tabular}{lcccc}
\hline Validity test & $\mathrm{aVL}$ & $\mathrm{I}+\mathrm{aVL}$ & $\mathrm{V}_{1}$ & $(\mathrm{I}+\mathrm{aVL})$ with $\mathrm{V}_{1}$ \\
\hline Sensitivity & 75.0 & 87.5 & 87.5 & 100.0 \\
Specificity & 33.3 & 30.0 & 66.7 & 13.3 \\
PPV & 47.4 & 50.0 & 66.7 & 48.0 \\
NPV & 62.5 & 75.0 & 87.5 & 100.0 \\
\hline
\end{tabular}

\section{Discussion:}

This observational study was conducted from April 2009 to December 2010, in the Department of Cardiology, Bangabandhu Sheikh Mujib Medical University (BSMMU), and Ibrahim Cardiac Hospital \& Research Institute, Dhaka. Patients of inferior wall AMI due to suspected RCA occlusion were admitted who subsequently underwent coronary angiography in the same hospital admission setting were included. ST-segment changes in lateral leads (I \& aVL) as well as in precordial lead $\left(\mathrm{V}_{1}\right)$ correlated with angiographic site of lesion.

Mean $( \pm$ SD) age of the study population was $57.9 \pm 10.2$ years with male to female ratio 3.1:1. Study of the common risk factors for coronary artery disease showed that smoking was the commonest one followed by hypertension, diabetes mellitus, dyslipidaemia and family history of CAD. Distribution of common risk factors between male and female was statistically non-significant except diabetes $(\mathrm{p}<0.05)$.These data were almost similar to those of the study done in Bangladesh and abroad. Analysis of presenting complaints showed that, the highest percentage of the patients had chest pain followed by shortness of breath, sweating, nausea or vomiting and dizziness were more prevalent in proximal RCA occlusion. On average patients attended the hospital within 7.1 \pm 2.2 hours after onset of chest pain. Among the studied patients, the most frequent complication was hypotension (23.3\%). The most frequently observed conduction disturbance was complete heart block. Complete heart block and first degree hart block were more prevalent in group I. All the patients were evaluated echocardiographically to see the left ventricular ejection fraction in this study. Most (63.3\%) patients had LVEF between to 50-60\% in group I and 54.2\% of patients belong had LVEF $50-60 \%$ in group II. A higher percentage of patients in group II had LVEF less than $50 \%$. In this study, proximal RCA lesion was more prevalent than distal RCA lesion with a ratio of 1.3 .
This study revealed that among the group I patients having ST-segment iso electric or elevated in lead $V_{1}$ were $66.7 \%$ and depressed in lead $\mathrm{V}_{1}$ were $33.3 \%$, whereas among group II patients with ECG findings ST-segment iso electric or elevated in lead $\mathrm{V}_{1}$ were $12.5 \%$ and depressed in lead $\mathrm{V}_{1}$ were $87.5 \%$. A statistically significant difference was found between two groups of patients ( $\mathrm{p}<0.05)$. So, it is assumed that ST-segment in lead $V_{1}$ iso electric/elevated or depressed is a useful predictor of RCA occlusion in acute inferoposteior MI. Patients having the ECG criteria 'ST-segment iso electric or elevated in lead $\mathrm{V}_{1}$ ' $66.7 \%$ had culprit lesion in proximal RCA whereas patients with criteria 'ST-segment depressed in $\mathrm{V}_{1}$ ' $87.5 \%$ had culprit lesion in distal RCA. The degree of ST-segment deviation in lead $\mathrm{V}_{1}$ can differentiate the site of RCA occlusion in inferior wall acute M. ${ }^{9,10,16}$

Celik et al. also found that ST-segment elevation in lead $\mathrm{V}_{1}$ suggesting culprit lesion was in proximal RCA. Similar reports were given by Moye et al. ${ }^{14}$

In this study, 'ST-segment in lead $\mathrm{V}_{1}$ iso electric or elevated predicts the proximal RCA with sensitivity, specificity, positive \& negative predictive value of $66.7 \%, 87.5 \%, 87.5 \%$ and $66.7 \%$ respectively.

Depressed ST-segment in lead $\mathrm{V}_{1}$ predicts the distal RCA with sensitivity, specificity, positive \& negative predictive value of $87.5 \%, 66.7 \%, 66.7 \%$ and $87.5 \%$ respectively. Fiol et al. found that, the sensitivity, specificity, positive \& negative predictive value of ST-segment iso electric or elevated in lead $\mathrm{V}_{1}$ for detection of proximal RCA lesion were $70 \%, 87 \%, 87 \%$ and $71 \%$ respectively and of STsegment depressed in $\mathrm{V}_{1}$ for detection of distal RCA lesion were $90 \%, 71 \%, 70 \%$ and $91 \%$ respectively.

The combination of two criteria was analyzed together. This study revealed that sum of ST-segment depression in leads I \& aVL e" $5.5 \mathrm{~mm}$ and ST-segment iso electric or elevated in $\mathrm{V}_{1}$ has increased the specificity \& positive predictive value to $100 \%$ to detect proximal RCA occlusion, 
but on the other hand, the sensitivity decreased to $13.3 \%$. Sum of ST-segment depression in leads I \& aVL $<5.5 \mathrm{~mm}$ and ST-segment depressed in $\mathrm{V}_{1}$ has increased the sensitivity \& negative predictive value to $100 \%$ to detect distal RCA occlusion but on the other hand, specificity decreased to $13.3 \%$ which significantly decrease the utility of this criteria in clinical practice. Almost similar reports were given by Fiol et al. ${ }^{9}$

\section{Conclusion:}

This study assessed the predictive value of admission electrographic changes to predict the site of right coronary artery occlusion (proximal or distal RCA) in inferoposterior wall AMI as determined by coronary angiography.

It was demonstrated that, ST-segment changes in precordial lead $\left(\mathrm{V}_{1}\right)$ is a sensitive \& specific marker to discriminate proximal \& distal RCA occlusion in inferoposterior wall AMI with high positive \& negative predictive value, but ST-segment changes in lateral leads (I \& aVL) although more specific for proximal RCA occlusion does not seem to be of clinical value due to its low sensitivity.

\section{Recommendations:}

From this study it may be recommended that, ST-segment changes in lead $\mathrm{V}_{1}$ on admission ECG can be used in patients with inferoposterior MI due to suspected RCA occlusion in the emergency room or coronary care unit to predict the site of RCA lesion, which is very important for risk assessment and for choice of therapy. Further study may be conducted on these ECG criteria on large sample size.

\section{Study Limitations:}

This was a nonrandomized study.

Sample size was small.

Coronary angiography was evaluated by visual estimation.

\section{Acknowledgement:}

We are grateful to Prof. M. Maksumul Haque, Consultant and Head of the Department, Ibrahim Cardiac Hospital \& Research Institute for his kind permission, encouragement and advice to undertake this study in ICH \& RI.

\section{Refferences:}

1. Braat SH, de Zwaan C, Brugada P, Joseph M, Coenegracht and Wallens HJJ. 'Right ventricular involvement with acute inferior wall myocardial infarction identifies high risk of developing atrioventricular nodal conduction disturbances', Am Heart J, 1984; 107: 1183-87.

2. Bairey CN, Shah PK, Lew AS, Hulse S. 'Electrocardiographic differentiation of occlusion of the left circumflex versus the right coronary artery as a cause of inferior acute myocardial infarction', Am J Cardiol, 1987; 60: 456-59.

3. Berry C, Zalewsky A, Kovach R, savage M, Goldberg S. 'Surface electrocardiogram ischaemia during coronary artery occlusion’, Am J Cardiol, 1989; 63: 21-26.

4. Boersma, E, Mircardo, N, Polderman, D. Gardien, M. Vos, J \& Simons, ML. 'Acute myocardial infarction', Lancet, 2003; 361: 847-58.

5. Berger PB, Ryan TJ. 'Inferior myocardial infarction: High risk subgroups’, Circulation, 1990; 81: 401-11.

6. Chia BL, Yip JW, Tan HC and Lim YT. 'Usefulness of ST elevation II/III ratio and ST deviation in lead I for identifying the culprit artery in inferior wall acute myocardial infarction', Am J Cardiol, 2000; 86: 341-43.

7. Celik, T, Yuksel, C, Kursaklioglu, H, Kose, S \& Isik, E. 'Precordial ST- segment elevation in acute occlusion of the proximal right coronary artery', Journal of electrocardiology, 2006; 39: 301-4.

8. Fiol, M, Carrillio, A, Cygankiewicz, I, Ayestaran J, Caldes O, Peral, V, Bethencourt, A, Zareba, W and Luna, AB. 'New criteria based on ST changes in surface ECG to detect proximal versus distal right coronary artery occlusion in a case of acute inferoposterior myocardial infarction', Ann Noninvas Electrocardiol, 2004; 9: 383-8.

9. Fiol M, Cygankiewicz I, Guindo J, Flotats, A, Genis, AB, Carreras, F, Zareba, W, Luna, AB. Evolving myocardial infarction with ST elevation: ups and downs of ST in different leads identifies the culprit artery and location of the occlusion. Ann Noninvas Electrocardiol, 2004: 9: 180-6.

10. Griffin, BP and Topol EJ. 'The mannual of cardiovascular medicine, $3^{\text {rd }}$ edn, Lippincott, Philadelphia, USA. 2009, 0125.

11. Hasdai D, Birnbaum Y, Herz I, Sclarovsky S, Mazur A, Solodky A. 'ST segment depression in lateral limb leads in inferior wall acute myocardial infarction', Eur Heart J, 1995; 16: 154955.

12. Herz I, Assali A, Adler Y, Flontats A, Genis AB, Carreeras F, Zareba W, Luna AB, 'New electrocardiographic criteria for predicting either the right or left circumflex artery as a culprit coronary artery in inferior wall acute myocardial infarction', Am J, Cardiol, 1997; 80: 1343-45.

13. Kosuge M, Kimura K, Ishikawa T, Hongo Y, Shigemasa T, Sugiyama M, Tochikubo O, Umemura S. 'Implications of the absence of ST segment elevation in lead V4R in patients who have inferior wall acute myocardial infarction with right ventricular involvement', Clin Cardiol, 2001; 24: 225-30.

14. Moye, S, Carney, MF, Holstege, C, Mattu, A, Brady, WJ. 'The electrocardiogram in right ventricular myocardial infarction', Am J Emerg Med, 2005; 23: 793-99.

15. Turhan H, Yilmaz MB, Yetkin E,Atak R, Biyikoglu SF, Senen K, Ileri M, Cehreli S, Korhmaz S, Kutuk E, ‘ Diagnostic value of aVL derivation for right ventricular involvement in patients with acute myocardial infarction', Ann Noninvasiv Electrocardiol, 2003; 8: 185-89.

16. Tsuka, Y, Sugiura, T, Hadata, K, Nakamura, S, Yuasa, F \& Iwasaka, T. 'Clinical significance of ST segment elevation in $\mathrm{V}_{1}$ in patients with acuta inferior wall Q- wave myocardial infarction', Am Heart J, 2001; 141: 615-20.

17. Zehender, MP, Kasper S \& Kauder, T. 'Right ventricular infarction as an independent predictor of prognosis after acute myocardial infarction', $N$ Engl $J$ Med, 1993; 328: 981-88. 